\title{
Does resource availability affect host manipulation? - an experimental test with Schistocephalus solidus
}

\author{
NINA HAFER ${ }^{*}{ }^{1}$ and DANIEL P. BENESH ${ }^{1,2}$ \\ ${ }^{1}$ Department of Evolutionary Ecology, Max Planck Institute for Evolutionary Biology, August-Thienemann-Straße 2, \\ 24306 Plön, Germany \\ ${ }^{2}$ Marine Science Institute, University of California, Santa Barbara, California 93106-6150, USA
}

(Received 17 Fune 2015; revised 20 August 2015; accepted 20 August 2015)

SUMMARY

Host manipulation is a common strategy of parasites employed to increase their fitness by changing the phenotype of their hosts. Whether host manipulation might be affected by environmental factors such as resource availability, has received little attention. We experimentally infected laboratory-bred copepods with the cestode Schistocephalus solidus, submitted infected and uninfected copepods to either a high or a low food treatment, and measured their behaviour. Infection reduced host activity and speed in both feeding treatments. However, the difference between the infected and uninfected copepods was smaller under low food conditions, because uninfected, but not infected, copepods moved slower under these conditions. We suggest that these differences are mediated by the physical condition of copepods rather than changes in how strongly the parasite manipulated host behaviour. Additionally, we measured three fitness-relevant traits (growth, development and infection rate in the next host) of the parasite to identify potential trade-offs with host manipulation. The largest parasites in copepods appeared the least manipulative, i.e. their hosts showed the smallest behavioural alterations, but this may again reflect variation in copepod condition, rather than life history trade-offs between parasite growth and host manipulation. Our results point to the possibility that parasite transmission depends on environmental conditions.

Key words: Host manipulation, environmental effects, costs, life history trade-offs, experimental infections, cestode, copepod.

\section{INTRODUCTION}

The environment organisms experience is rarely uniform; it varies over time and space. This applies to both free-living organisms and their parasites. Environmental stressors can reshape host-parasite interactions in various ways depending on the species and stressors involved (Lafferty and Kuris, 1999). Many parasites enhance their fitness by changing the behaviour of their host (reviewed by Holmes and Bethel, 1972; Poulin and Thomas, 1999; Moore, 2002, 2013; Poulin, 2010). Such host manipulation is well-known in complex life cycle parasites, where it not only serves to enhance transmission to a target host (predation enhancement), but also to avoid fatal predation before the parasite reaches infectivity (predation suppression) (Hammerschmidt et al. 2009; Parker et al. 2009; Dianne et al. 2011; Thomas et al. 2011; Weinreich et al. 2013). Such host manipulation could also be influenced by the host's environment ('Thomas et al. 2012). Biotic factors such as predator cues (e.g. Jakobsen and Wedekind, 1998; Baldauf et al. 2007; Durieux et al. 2012; Dianne et al. 2014) or

* Corresponding author: Department of Evolutionary Ecology, Max Planck Institute for Evolutionary Biology, August-Thienemann-Straße 2, 24306 Plön, Germany. Phone: + 494522 763-347. Fax: +49 4522 763-310. E-mail: hafer@evolbio.mpg.de the presence of other parasites (Cézilly et al. 2000, 2014; Haine et al. 2005; Dianne et al. 2010; Hafer and Milinski, 2015) can influence host manipulation. Differences in abiotic factors might also play a role. In isopods infected by an acanthocephalan parasite, host manipulation changes between seasons, but this does not seem to be caused by either temperature or lighting conditions but might rather be related to host or parasite age (Benesh et al. 2009). Resource availability, too, could affect host manipulation. Hungry and satiated hosts can differ in the extent of parasite-altered behaviour they show (e.g. Giles, 1987; Barber et al. 1995; Jakobsen and Wedekind, 1998). If the existence and efficacy of host manipulation varies with particular environmental factors, then parasite transmission rates will differ between environments. An evolutionary consequence of this is that the benefits of and selection for host manipulation will vary across time and/or space (Franceschi et al. 2010b).

Host manipulation can result in energetically costly behaviour such as increased activity (reviewed by Poulin, 1994a). Resource limitation will reduce a host's ability to perform such behaviours (Thomas et al. 2011, 2012). Limited resources could also reduce host manipulation, if parasites need to use energy to manipulate and are limited by the available resources of their host. Energetic costs of host manipulation have often been assumed, because

Parasitology Open (2015), Vol. 1, e3; page 1 of 10. (C) Cambridge University Press 2015. This is an Open Access article, distributed under the terms of the Creative Commons Attribution licence (http://creativecommons.org/licenses/by/4.0/), which permits unrestricted re-use, distribution, and reproduction in any medium, provided the original work is properly cited. 
parasites might use some substance they have to produce and emit to manipulate their hosts (Poulin, 1994b, 2010; Biron et al. 2005; Thomas et al. 2005, 2011; Vickery and Poulin, 2009); but these have yet to be convincingly demonstrated. Potential trade-offs between the level of host manipulation and other important parasite traits could hint at such a cost (Franceschi et al. 2010a; Maure et al. 2011). Alternatively, host manipulation could increase under resource limitation. For example, lack of resources could impair a host's defences against manipulation (Roitberg, 2012). Another way for manipulation to increase under resource limitation is if parasites affect host behaviour by draining energy from the host (reviewed by Adamo, 2012; Lafferty and Shaw, 2013). Energy drain shifts the trade-off between predator avoidance and feeding towards feeding and might hence resemble host manipulation that serve to increase a host's predation susceptibility (Milinski, 1990).

Schistocephalus solidus has a three host life cycle consisting of a cyclopoid copepod, a three-spined stickleback and a piscivorous bird (Clarke, 1954; Dubinina, 1980). At $18^{\circ} \mathrm{C}$ it spends about 2 weeks in copepods before it is ready for transmission (i.e. infective) to the next host, which takes place when the copepod is consumed by a stickleback. During this time, it reduces the activity (Hammerschmidt et al. 2009; Benesh, 2010a; Hafer and Milinski, 2015) and predation susceptibility (Weinreich et al. 2013) of its host. In a previous study (Benesh and Hafer, 2012), we investigated the effect of the performance of $S$. solidus in its copepod host (i.e. growth and development) on performance in the fish host (e.g. infection success and growth). To create variation in copepod quality, we used two different feeding treatments which differed in food quantity, but not quality. Here, we report the impact of these feeding treatments on the behaviour of infected and uninfected copepods. In addition, we explored potential trade-offs between host manipulation and other life history traits that could hint at an energetic cost to host manipulation.

\section{METHODS}

\section{Schistocephalus solidus and infection}

Schistocephalus solidus originated from Lake Skogseidvatnet, Norway. They were obtained by dissecting wild-caught three-spined sticklebacks (Gasterosteus aculeatus) and breeding the adult parasites in pairs in an in vitro system (Smyth, 1946). Tapeworm eggs were stored in the fridge $\left(4^{\circ} \mathrm{C}\right)$ until use, incubated for 3 weeks at $20^{\circ} \mathrm{C}$, and then exposed to light over night to induce hatching (Dubinina, 1980). Infection took place by exposing copepods to one coracidium each. Copepods that were used as uninfected controls received no coracidia but were otherwise treated the same.

\section{Copepod maintenance}

We used copepods (Macrocyclops albidus) from a laboratory stock that originated from the same population as S. solidus (Lake Skogseidvatnet, Norway). On the day prior to infection they were distributed on 24-well microtitre plates with about $1 \mathrm{~mL}$ of water. Copepods were maintained at $18{ }^{\circ} \mathrm{C}$ in a $16 /$ $8 \mathrm{~h}$ light/dark cycle and fed with Artemia sp. naupili every other day. Copepods in the high food treatment $(\mathrm{H})$ received four Artemia at each feeding, while copepods in the low food treatment (L) received two (Fig. 1). These treatments were sufficient to affect copepod mortality and parasite growth in other experiments (Benesh, 2010b). In our experiment, the high food treatment led to faster parasite development, faster growth and higher infection success in one experimental group (day-11 copepods). In a second experimental group (day-17 copepods), the high food treatment only significantly improved parasite growth but not development or infection success (See Supplementary information).

\section{Measurements of parasite performance}

Copepods are transparent making it possible to view and measure a parasite in vivo (Wedekind et al. 2000; Benesh et al. 2012). We checked copepods for infection 6-8 days post infection (dpi). Parasites were additionally checked inside their hosts for the presence or absence of a cercomer $9 \mathrm{dpi}$. Although the function of the cercomer is unknown, it is a good indicator for parasite development and the ability to infect fish (Smyth and McManus, 1989). The parasites used in this study were more likely to infect fish $11 \mathrm{dpi}$ if they had a cercomer $9 \mathrm{dpi}$ than if they did not (Benesh and Hafer, 2012). On the day prior to exposure to fish (10 or $16 \mathrm{dpi}$ ), we measured the size of the parasite. This took place by photographing each parasite twice within its host under a microscope. From these photographs, we measured the area of the parasite (without cercomer) using image J (Rasband, 2008) and took the average from these two measurements. Three-spined sticklebacks (G. aculeatus) were individually exposed to a single copepod, either 11 (day-11 copepods) or 17 (day17 copepods) dpi. Any potential trade-off between manipulation and the ability to infect fish should be especially crucial $11 \mathrm{dpi}$, since at this time only the fastest developing $S$. solidus might be ready to infect the next host (Hammerschmidt et al. 2009; Benesh and Hafer, 2012). By $17 \mathrm{dpi}$, nearly all $S$. solidus are morphologically well-developed (Benesh, 2010b) and ready to infect fish (Benesh and Hafer, 2012). Approximately 4 weeks after exposure, we dissected the fish to determine infection success (see Benesh and Hafer, 2012). Fish experiments were conducted with the permission of the 


\section{Day-11 copepods}

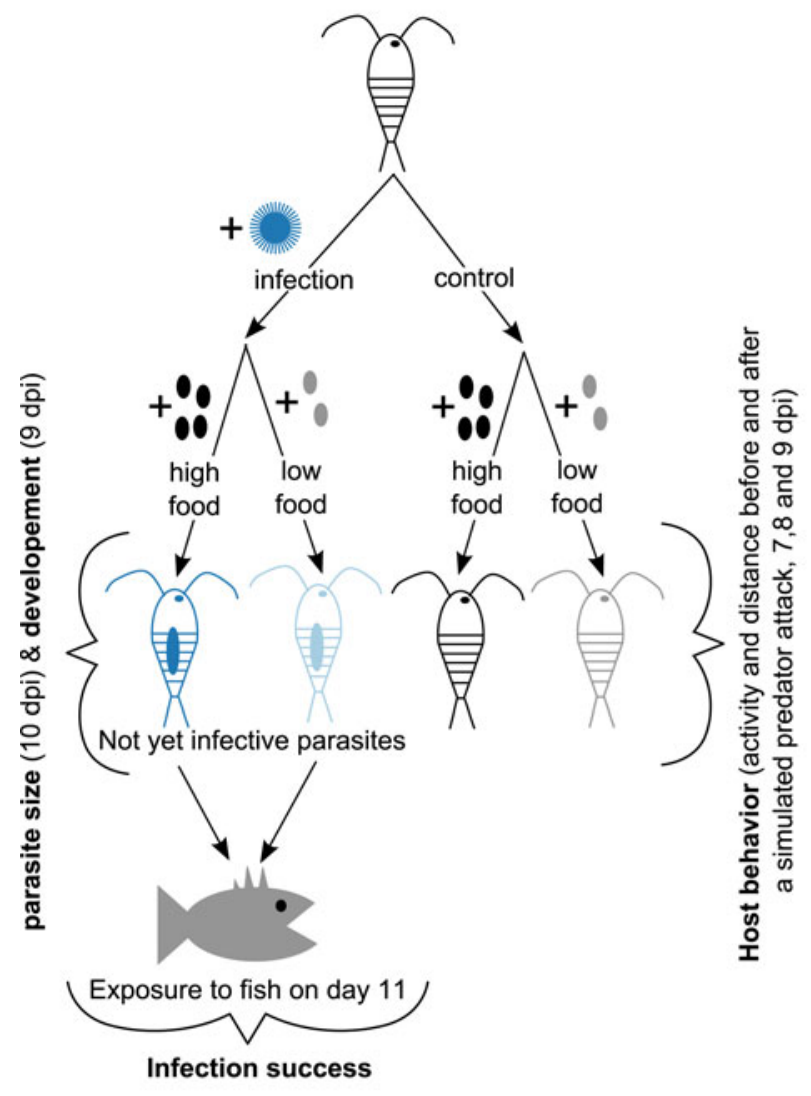

Day-17 copepods

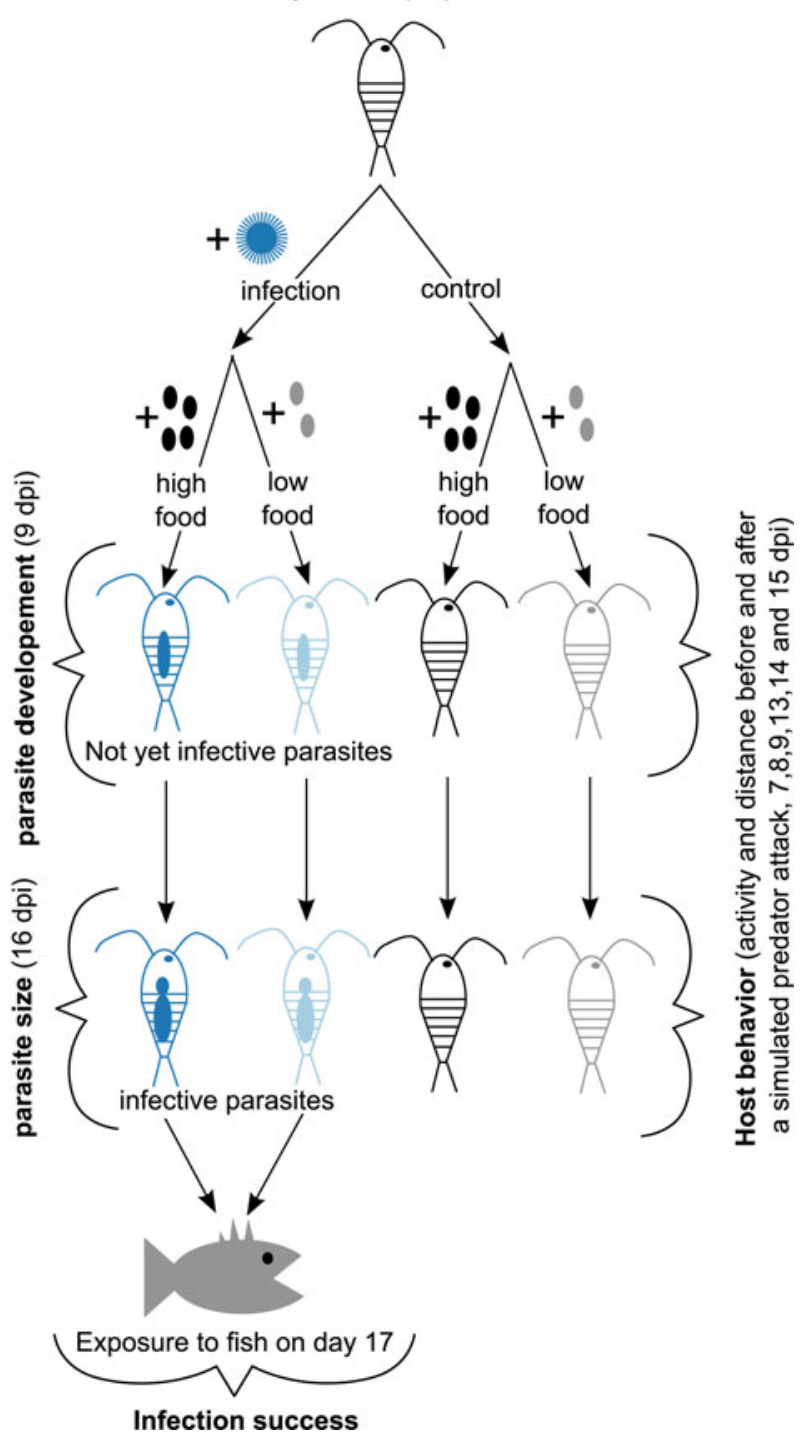

Fig. 1. Overview of the experimental setup. Copepods were either exposed to S. solidus coracidia or not, subjected to a high or a low food treatment and exposed to fish at two different time points, $11 \mathrm{dpi}$ (day-11 copepods) or $17 \mathrm{dpi}$ (day-17 copepods). We measured three aspects of parasite performance: development and size in copepods and infection success in fish. We measured two aspects of copepod behaviour: activity (i.e. proportion of time copepods spent moving) and, when moving, the distance moved.

'Ministry of Energy, Agriculture, the Environment and Rural Areas' of the state of SchleswigHolstein, Germany (reference number: V 31372241·123-34).

\section{Copepod behavioural measurements}

Schistocephalus solidus has to spend between 10 days and 2 weeks at $18{ }^{\circ} \mathrm{C}$ in its copepod host before it becomes infective to sticklebacks, at which time host manipulation switches from predation suppression to predation enhancement (Hammerschmidt et al. 2009; Hafer and Milinski, 2015). This switch is not obvious in all populations and some populations show no clear predation enhancement, including the population used in this study (Benesh, 2010a). We measured behaviour on multiple days and grouped the observations into two age groups: behaviour 7, 8 and 9 dpi (parasite is not yet infective to fish) and 13,14 and 15 dpi (infective parasite, only recorded for the day-17 copepods). We mostly focus on predation suppression, which should occur 7,8 and 9 dpi when parasites should not yet be infective. Multiple observations help to more accurately quantify an individual's typical behaviour and make correlations between host manipulation and other parasite traits more robust (Benesh et al. 2008).

Each well plate with copepods was gently placed on an apparatus that dropped it by $3 \mathrm{~mm}$ in a standardized way to simulate a predator attack (see Hammerschmidt et al. 2009). Once the plate had been on the apparatus for a $1 \mathrm{~min}$ acclimation period, we started recording copepod behaviour using a video camera (Panasonic Super 
DynamicWV-BP550, Panasonic Corporation, Osaka, Japan). Copepods were recorded for $90 \mathrm{~s}$, then the plate was dropped and copepods were recorded for an additional $90 \mathrm{~s}$. We split the recordings into $2 \mathrm{~s}$ intervals (90 observations per copepod per recording event). Preliminary analyses found that little extra movement was recorded with shorter intervals. Using the manual tracking plugin within image J (Rasband, 2008), we recorded whether or not each copepod moved within each of these $2 \mathrm{~s}$ intervals (activity) and, if so, how far it moved (distance). We only analysed the behaviour of exposed and infected and unexposed and uninfected copepods that survived until the day that its treatment group was used to infect fish (11 or 17 dpi). We did not record the behaviour of exposed but uninfected copepods, because previous studies indicated they do not differ from unexposed controls (Hammerschmidt et al. 2009; Benesh, 2010a). In total we recorded the behaviour of 382 copepods (day-11 copepods: infected: H: 65, L: 68, uninfected: H: 45, L: 44; day-17 copepods: infected: H: 51, L: 51, uninfected: H: 30, L: 28).

\section{Statistical analysis}

We analysed copepod behaviour at a fine scale, i.e. each $2 \mathrm{~s}$ observation. Thus, we had repeated observations on the same copepod at two levels: within a recording event (i.e. each copepod on a given day) and across recording events on different days. To analyse copepod activity (proportion of $2 \mathrm{~s}$ intervals spent moving), we used generalized linear mixed models with binomial error family in the lme4 package (Bates et al. 2014) in R (R Development Core Team, 2010). To analyse the distance copepods moved, we included only data from when movement had occurred. We used linear mixed models (lme4 package, Bates et al. 2014) in R (R Development Core Team, 2010) after log transforming the distance. To account for variation between individual copepods over days we included copepod identity into the random effects. Additionally, we included the recording event to account for variation within days during the recording event together with the time interval in the recording (before $v s$ after the simulated predator attack) to account for differences before and after the simulated predator attack. For day-17 copepods, we included an additional term, 'age', in the 'copepod identity' random effect. Age distinguished behavioural observations made early (7-9 dpi, i.e. parasites were not yet infective to fish) from those made later $(13-15 \mathrm{dpi}$, i.e. when parasites were likely to be infective to fish). This term quantifies how the behaviour of individual copepods changes over time and as such applies to both, infected and uninfected copepods. Specifically for infected copepods it shows how behaviour changes as their parasites mature (see Table 1 for more details on the model). Both, time interval (i.e. before $v s$ after the simulated predator attack) and age (only day-17 copepods) were also included as fixed effects. We stepwise added infection, feeding treatment and their pairwise interactions with each other and with time interval and age (only day-17 copepods). We compared models using likelihood ratio tests. We accepted a model as having a better fit than a less complicated one if it explained the data significantly better as judged by likelihood ratio tests. See Table 1 for the details and outputs of the models. We fitted separate models for day-11 and day-17 copepods since only the later included the behaviour of copepods, that, if they were infected, harboured infective parasites (age 13-15 dpi). If we found any significant interactions between infection and feeding, we conducted Tukey post hoc tests. For post hoc tests, we used the same models described above but combined infection and feeding into a single factor whose levels comprised all possible combinations of these two factors and removed all other interactions involving feeding or infection from the model. On these models we applied general linear hypotheses within the multcomp package in R (Hothorn et al. 2008). For all other statistics and more detailed information on the models used please refer to Table S1.

To investigate a potential association between copepod behaviour and parasite size, development (i.e. presence or absence of a cercomer on day 9) and infection success in fish, we used the same mixed models described above except we limited them to infected copepods. We added the parasite performance traits (size, development and infection success) to the models, as well as their interactions with the other fixed factors, and performed likelihood ratio tests (see Table S2). Since this involved multiple comparisons we took adjusted $P$-values (after bonferroni) into account when we found any significant differences.

\section{RESULTS}

\section{Confirmation of the effect of parasite infection on copepod behaviour}

Schistocephalus solidus reduces the predation susceptibility of its copepod host before reaching infectivity (Weinreich et al. 2013). This is marked by a reduction in activity (Hammerschmidt et al. 2009; Benesh, 2010a; Hafer and Milinski, 2015) which we also found in our study (Fig. 2A and B, $P<$ $0 \cdot 0002$, Table 1). In day-17 copepods there was an interaction between infection and age (i.e. 7-9 dpi vs 13-15 dpi, $P=0 \cdot 0141$, Table 1). Differences between infected and uninfected copepods were more pronounced at an earlier age, i.e. before the parasites reached infectivity (Fig. 2B). This is in line with previous predictions (Parker et al. 2009) 
Table 1. Outcome of likelihood ratio tests for generalized linear models of copepod activity (i.e. proportion of time spent moving) and the distance copepods moved when moving

\begin{tabular}{|c|c|c|c|c|c|c|c|}
\hline & \multirow[b]{2}{*}{ Factors } & \multicolumn{3}{|c|}{ Activity } & \multicolumn{3}{|c|}{ Distance } \\
\hline & & D.F. & $\chi^{2}$ & $P$ & D.F. & $\chi^{2}$ & $P$ \\
\hline Day-11 copepods & $\begin{array}{l}\text { + INFECTION } \\
\text { +INFECTION:INTERVAL } \\
\text { +FEED } \\
\text { +FEED:INTERVAL } \\
\text { +FEED:INFECTION }\end{array}$ & $\begin{array}{l}1,7 \\
1,8 \\
1,9 \\
1,10 \\
1,11 \\
5623 \\
\mathrm{RE}\end{array}$ & $\begin{array}{l}87 \cdot 180 \\
8 \cdot 651 \\
0 \cdot 059 \\
7 \cdot 497 \\
0 \cdot 680 \\
\text { bservati } \\
222 \text { col }\end{array}$ & $\begin{array}{l}<\mathbf{0 . 0 0 0 1} \\
\mathbf{0 \cdot 0 0 3 3} \\
0 \cdot 8082 \\
\mathbf{0 \cdot 0 0 6 2} \\
0 \cdot 4094 \\
\text { on } 639 \\
\text { ods }\end{array}$ & $\begin{array}{l}1,8 \\
1,9 \\
1,10 \\
1,11 \\
1,12 \\
2476 \\
\text { RE }\end{array}$ & $\begin{array}{l}73 \cdot 990 \\
0 \cdot 820 \\
20 \cdot 952 \\
5 \cdot 253 \\
5 \cdot 164 \\
\text { bservati } \\
\text { d } 222 \text { col }\end{array}$ & $\begin{array}{l}<0 \cdot 0001 \\
0 \cdot 365 \\
<0 \cdot 0001 \\
\mathbf{0} \cdot \mathbf{0 2 1 9} \\
\mathbf{0} \cdot \mathbf{0 2 3 1} \\
\text { on } 635 \\
\text { ods }\end{array}$ \\
\hline Day-17 copepods & $\begin{array}{l}\text { + INFECTION } \\
\text { + INFECTION: INTERVAL } \\
\text { +INFECTION: AGE } \\
\text { +FEED } \\
\text { +FEED: INTERVAL } \\
\text { +FEED:AGE } \\
\text { +FEED:INFECTION }\end{array}$ & $\begin{array}{r}1,11 \\
1,12 \\
1,13 \\
1,14 \\
1,15 \\
1,16 \\
1,17 \\
7937 \\
\text { RE }\end{array}$ & $\begin{array}{l}16 \cdot 155 \\
0 \cdot 099 \\
6 \cdot 020 \\
2 \cdot 121 \\
0 \cdot 003 \\
0 \cdot 001 \\
1 \cdot 118 \\
\text { bservati } \\
160 \mathrm{col}\end{array}$ & $\begin{array}{l}\mathbf{0 \cdot 0 0 0 1} \\
0 \cdot 7533 \\
\mathbf{0 \cdot 0 1 4 1} \\
0 \cdot 1453 \\
0 \cdot 9605 \\
0 \cdot 9716 \\
0 \cdot 2903 \\
\text { on } 906 \\
\text { ods }\end{array}$ & $\begin{array}{c}1,12 \\
1,13 \\
1,14 \\
1,15 \\
1,16 \\
1,17 \\
1,18 \\
3266 \\
\text { RE }\end{array}$ & $\begin{array}{c}42 \cdot 062 \\
4 \cdot 572 \\
0 \cdot 212 \\
4 \cdot 859 \\
0 \cdot 013 \\
1 \cdot 476 \\
3 \cdot 868 \\
\text { bservati } \\
\text { d } 160 \text { col }\end{array}$ & $\begin{array}{l}<\mathbf{0} \cdot \mathbf{0 0 0 1} \\
\mathbf{0} \cdot \mathbf{0 3 2 5} \\
0 \cdot 2118 \\
\mathbf{0} \cdot \mathbf{0 2 7 5} \\
0 \cdot 9103 \\
0 \cdot 2244 \\
\mathbf{0} \cdot \mathbf{0 4 9 2} \\
\text { on } 879 \\
\text { ods }\end{array}$ \\
\hline
\end{tabular}

Whether or not a copepod moved within a two second interval (activity) or, if it moved, how far it moved (distance, $\log$ transformed) were our response variables. Copepod identity (ID), the recording event (RE, i.e. a combination of copepod identity and the day of the recording), and the time interval in the recording (i.e. before $v s$ after the simulated predator attack, INTERVAL) were used to construct the random effects. INTERVAL was additionally included as a fixed effect. For day-17 copepods we additionally included an AGE effect, which was, how long after exposure or shamexposure the behaviour was recorded (7-9 dpi, parasites not yet infective, vs 13-15 dpi, parasites infective), as both fixed and random effect (together with ID). Subsequently, we added whether or not copepods were infected (INFECTION) and which feeding treatment they received (FEED) and all their pairwise interactions with INTERVAL and AGE (day-17 copepods). Test statistics and MCMC-estimated $P$-values are for the comparison with the preceding model. Null model: day-11 copepods: INTERVAL + (INTERVAL $\mid$ RE) $+(1 \mid$ ID), day-17 copepods: INTERVAL + AGE + INTERVAL: AGE + (INTERVAL|RE) + (AGE|ID). Significant $P$-values have been marked in bold.

and findings that any predation suppression at least decreases as $S$. solidus becomes infective (Hammerschmidt et al. 2009; Benesh, 2010a; Hafer and Milinski, 2015). The distance which copepods moved was also significantly affected by infection with $S$. solidus (Fig. 2C andD, $P<0.0001$, Table 1); infected copepods moved shorter distances. Age did not significantly interact with infection (Table 1). There was some interaction between infection and how copepods responded to the predator attack (i.e. time interval, before $v s$ after a simulated predator attack) for activity in day-11 copepods $(P=0.0033$, Table 1$)$ and the distance copepods moved in day-17 copepods $(P=0.0325$, Table 1). In day-11 copepods, infected copepods reacted more strongly while in day-17 copepods infected copepods reacted less strongly than uninfected ones. However, both uninfected copepods and infected ones always showed the same, clear reaction to the simulated predator attack; they reduced their activity and the distance they moved (Figure S1). Accordingly, our results were not very sensitive to the time interval in the recording, i.e. differences between experimental treatments were not strongly contingent on whether copepods were observed before or after the simulated attack. Overall we can confirm that $S$. solidus alters the behaviour of its copepod host by decreasing its activity and the distance it moves.

\section{The effect of feeding on host behaviour and host manipulation}

If feeding treatment affects host manipulation, a significant interaction between feeding treatment and infection should occur. Neither this interaction nor feeding alone had any significant effect on copepod activity (Fig. 2A and B, Table 1). However, distance was affected by both feeding treatment (Fig. 2C and $\mathrm{D}, P<0.03$, Table 1$)$ and its interaction with infection (Fig. 2C and D, $P<0 \cdot 05$, Table 1). Feeding treatment affected uninfected copepods more strongly than infected ones (Fig. 2C and D). Post hoc tests reveal that uninfected copepods moved significantly slower if they were in the low food treatment than if they were in the high food treatment $(P<0.02$, Table S1). In infected copepods distance did not differ between feeding treatments (Table S1, Fig. 2C and D). Consequently, differences between infected and uninfected copepods were larger in the high food treatment than in the low food treatment (Table S2, Fig. 2C and D). This was not due to an effect of feeding treatments on parasites, but because of an effect on uninfected hosts. 


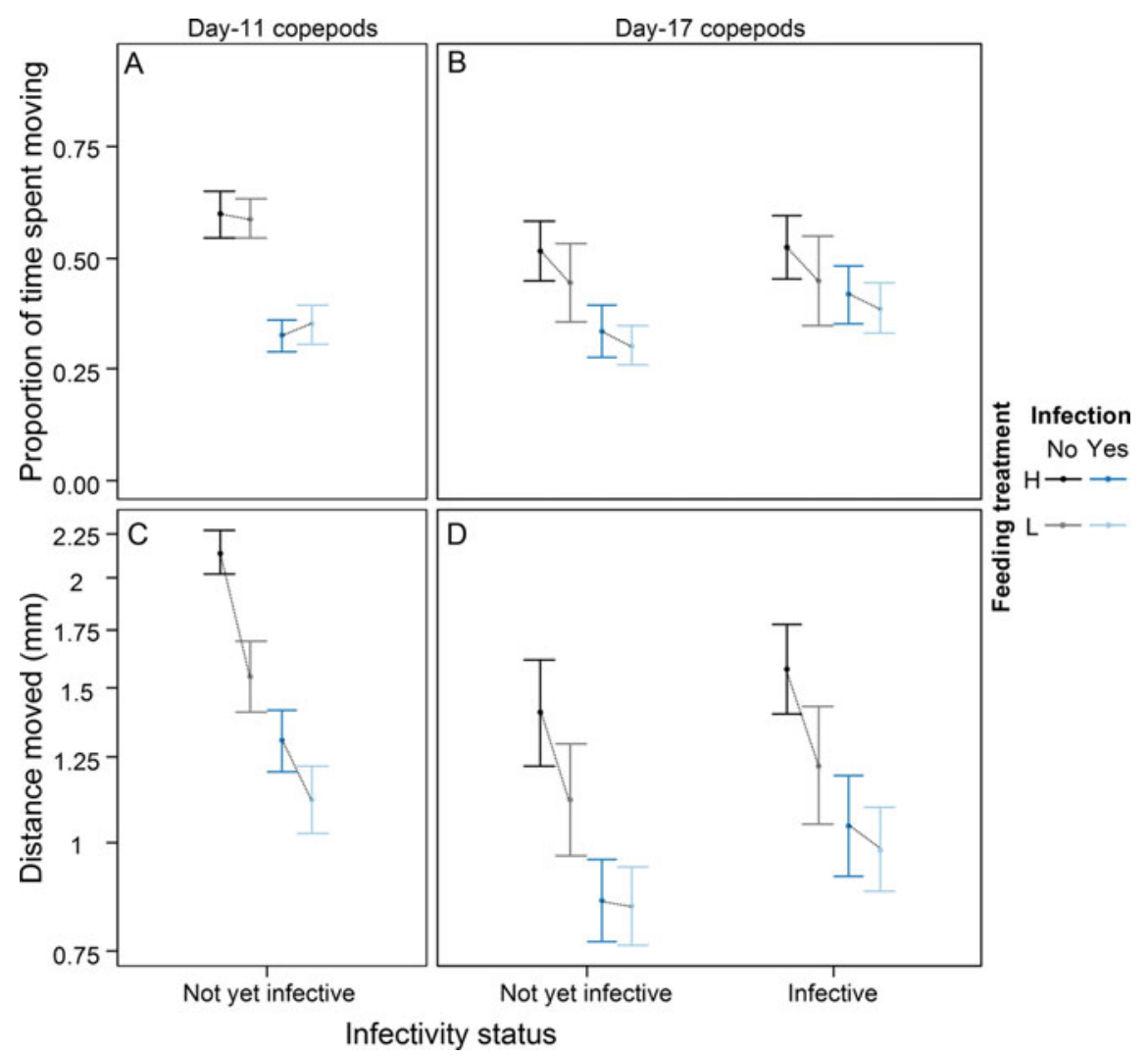

Fig. 2. Activity (A, B) and distance (C, D) as response to infection and feeding treatment. Error bars present means $+/-95 \%$ CI. Feeding treatment: H: high food treatment, L: low food treatment. N: day-11 copepods: not infected: H: 45, L: 44, infected: H: 65, L: 68, day-17 copepods: 7-9 dpi (parasites not yet infective): not infected: H: 30, L: 28, infected: H: 51, L: 49, day-17 copepods: 13-15 dpi (parasites infective): not infected: H: 30, L: 27, infected: H: 51, L:51. Dotted lines connecting groups are to aid comparison of feeding treatments, whereas the bar colours differentiate infection status. Age represents copepod behaviour 7-9 dpi (parasites not yet infective) vs 13-15 dpi (parasites infective).

\section{Associations between host manipulation and other fitness-related traits}

If host manipulation is costly and those costs lead to trade-offs with other fitness-related traits, parasites that manipulate less (i.e. behave more similar to uninfected hosts) should do better with regards to other traits such as growth or development.

\section{Parasite size and development}

Parasite size 10 dpi in day-11 copepods did not correlate with copepod activity (Table S2, Fig. 3A). However, there was a positive correlation between size and distance in day-11 copepods $(P=0 \cdot 0017$, adjusted $P$ value $=0.0204$, Table S1, Fig. 3C). Parasite size 16 dpi in day-17 copepods correlated positively with activity and distance $(P<0.003$, adjusted $P$ value $<0 \cdot 04$, Fig. 3B-D, Table S1). Copepods with larger parasites moved more often and further (Fig. 3B-D).

Development (presence or absence of a cercomer $9 \mathrm{dpi}$ ) was associated positively with activity in day-11 copepods (more active, i.e. less manipulated, copepods are more likely to have a cercomer $9 \mathrm{dpi}$,
$P=0.0103$, Table S1), but this association disappeared when correcting for multiple testing $(P=$ $0 \cdot 1236)$. Neither distance in day-11 copepods nor activity nor distance in day-17 copepods showed any association with parasite development (Table S2). Overall, the developmental rate did not seem to be associated with host behaviour.

\section{Infection probability in fish}

Parasites in day-11 copepods that moved further were more likely to have successfully infected fish 11 dpi $(P=0 \cdot 0049$, Table S2, Fig. 4C). When we adjusted for multiple testing, this finding was only marginally significant $(P=0 \cdot 0588)$. However, host activity was not associated with the parasite's probability to infect fish (Table S2, Fig. 4A). In day-17 copepods, we found no significant correlation between infection probability in fish and host behaviour (Table S2, Fig. 4). It appears that parasites that successfully infected fish came from hosts that moved larger distances, and hence were possibly less manipulated, but only if parasites were exposed to fish at the earlier time point (11 dpi). 


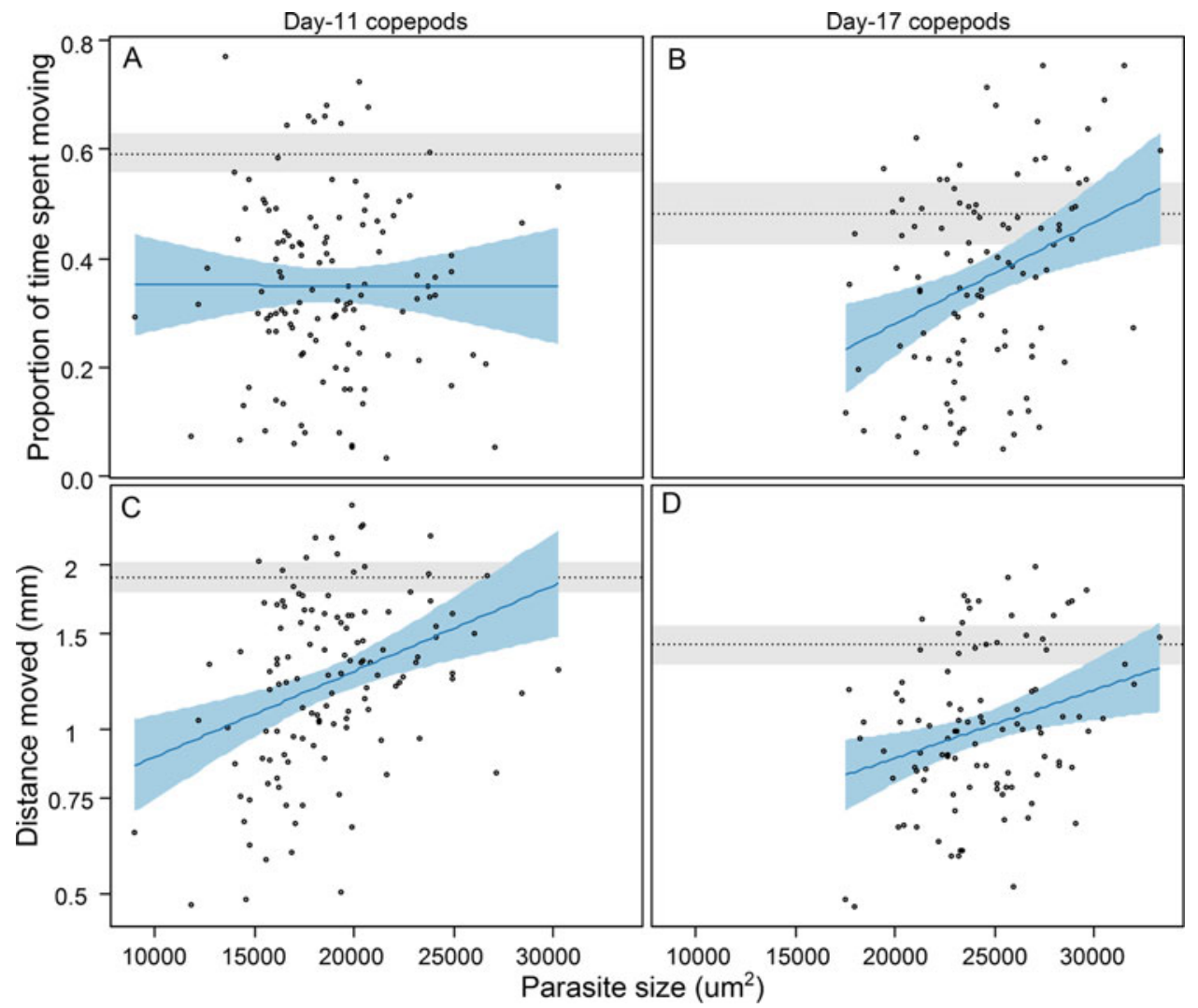

Fig. 3. The relationship between parasite size and host activity (A, B) and distance moved (C, D). Solid lines indicate the trend line. Dotted horizontal lines indicate mean behaviour of uninfected copepods. The shaded areas around the lines indicate $95 \%$ CI. Each dot represents the mean behaviour of one copepod calculated over all days on which its behaviour was recorded. N: day-11 copepods: 122, day-17 copepods: 102 .

\section{DISCUSSION}

Copepods infected with not yet infective $S$. solidus moved less and slower than uninfected copepods, which is compatible with predation suppression manipulation (Parker et al. 2009). This behavioural alteration seemed unaffected by resource availability, as infected copepods behaved similarly in low and high food treatments. Differences in feeding treatments also have no effect on host manipulation in acanthocephalan-infected gammarids (Labaude et al. 2015). In uninfected copepods, activity (i.e. proportion of time spent moving) is not affected by resource availability either, but they move less far in a low food than in a high food environment. As a result, behavioural differences between infected and uninfected copepods are less pronounced in a low food environment. Rather than changes in how much parasites manipulate, such an effect could be produced by differences in the condition of uninfected copepods between feeding treatments. Copepods that are in worse condition (e.g. because they have been limited in their resources) may be less able to invest in muscle tissue, limiting the distance they are able to move. Copepods that die sooner have less muscle tissue (Franz and Kurtz, 2002). Infected copepods already move less than uninfected ones, so it might not be practical for them to reduce their movement even further in a low food environment, since they still have to be able to e.g. forage.

If reduced physical condition is responsible for the reduced distance travelled by uninfected copepods under food constraints, could the modified behaviour of infected copepods also be caused by a decline in host condition, in this case due to parasite infection (see McElroy and de Buron, 2014)? Infection with $S$. solidus has no significant effect on either lipid storage or the amount of muscle tissue in the host (Franz and Kurtz, 2002). Other trophically-transmitted parasites have even been found to increase the energy reservoirs of their intermediate host (Amat et al. 1991; Plaistow et al. 2001; Ponton et al. 2005). Schistocephalus solidus not only reduces how far but also how often its host moves. The latter is not affected by feeding regime. Furthermore, an adverse effect of a parasite infection should increase with infection intensity. Host activity is not affected by the number of not yet infective $S$. solidus and even increases with the number of infective $S$. solidus (Hafer and Milinski, 2015).

We find no clear connection between cercomer presence 9 dpi (development) and host behaviour. However, host activity in day-17 copepods and distance in day-11 and day-17 copepods correlates 


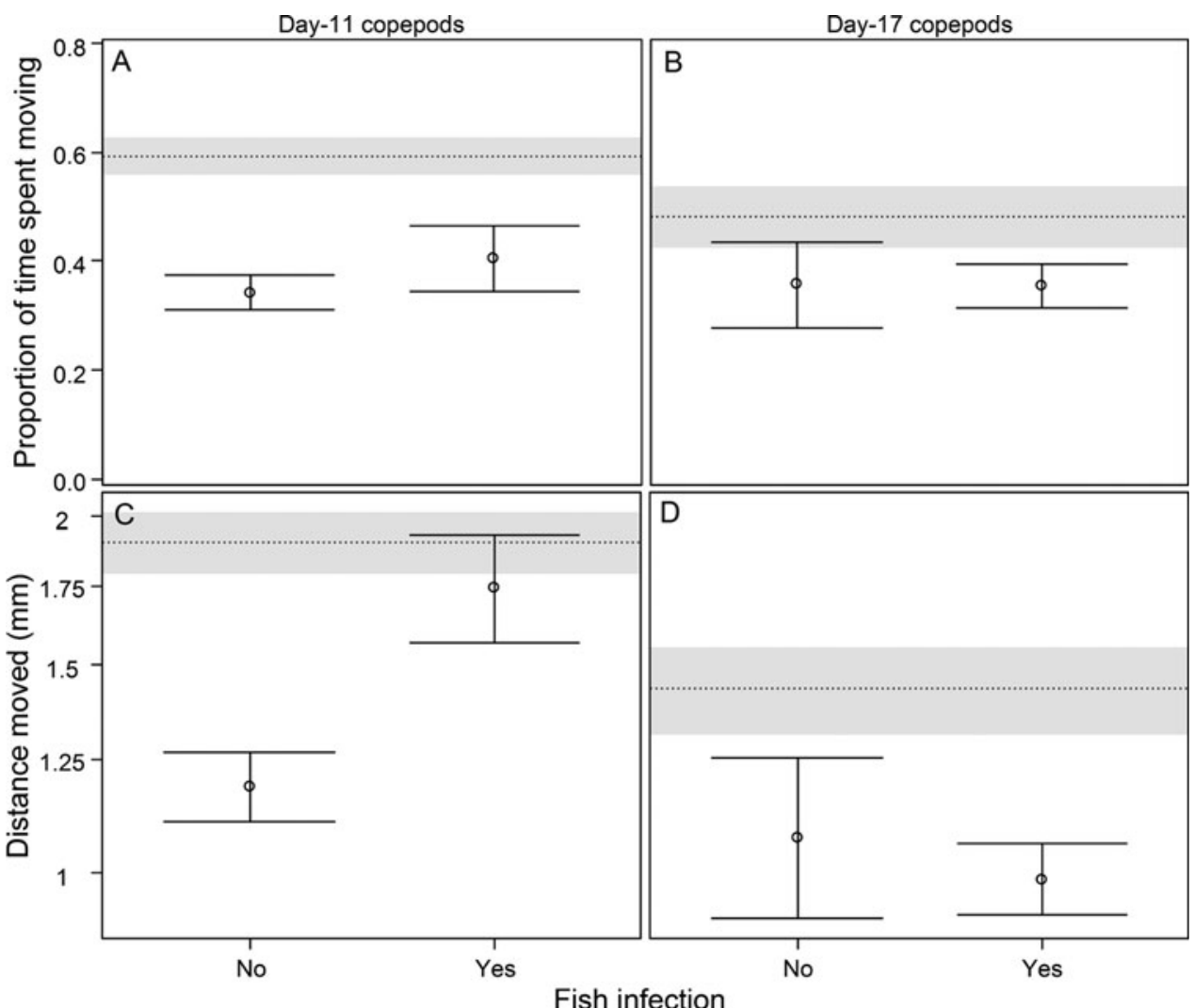

Fig. 4. Differences in activity (A, B) and distance moved (C, D) of copepods that successfully infected fish and those that did not. Error bars indicate $95 \%$ CI. Dotted horizontal lines indicate mean behaviour of uninfected copepods. The shaded areas around the lines indicate 95\% CI. N (fish infection successful/failed): day-11 copepods: 11/110, day-17 copepods: $81 / 18$.

positively with size 10 dpi (day-11 copepods) or 16 dpi (day-17 copepods). This is puzzling since Benesh $(2010 a)$ found no such correlations. On a family level, there was even a negative correlation between parasite size on day 11 and development and activity before reaching infectivity (Benesh, 2010a). Our food treatments possibly introduced more variation in parasite size and/or copepod behaviour that enhanced co-variation between them. A positive correlation between size and activity after reaching infectivity is in line with the finding that two infective $S$. solidus enhance the activity of their host more than one (Hafer and Milinski, 2015). Maybe this is not so much an effect of number as of size. However, there need not be any causal relationship between parasite size and host activity. Copepods in better physical condition might at the same time be able to move further and allow their parasites to grow to a larger size. Indeed, parasites whose hosts are in a high food treatment do grow larger (Benesh, 2010a, Supplementary information).

We found a trend for an association between infection rates in fish $11 \mathrm{dpi}$ and the distance copepods with not yet infective parasites moved. Parasites that successfully infected fish on day 11 came from copepods that had moved further (i.e. less 'predation suppression' manipulation) than those that failed to infect fish. This, however, need not imply any causal relationship between host manipulation and infection success. Previous studies have also reported a negative correlation between parasite fitness components and host manipulation, suggestive of trade-offs (Franceschi et al. 2010a; Maure et al. 2011). Since these studies are also correlational, alternative explanations cannot be ruled out. In our case, a trade-off may not be the best explanation. As discussed above, the distance which copepods move might be affected by their physical condition. It seems reasonable to assume that copepods that are in better physical condition can move further and can harbour rapidly growing parasites that are better at infecting fish. This will be especially crucial for parasites that are transmitted to fish early (i.e. $11 \mathrm{dpi}$ ) when they are just starting to become infective and there is still variation in developmental stage, and only the fastest developing parasites succeed in infecting fish. By 17 dpi even parasites in copepods in worse condition should have been able to catch up in their development and hence be able to infect fish (Benesh and Hafer, 2012).

Host manipulation can have important ecological consequences (Thomas et al. 1998, 1999, 2005; Lefèvre et al. 2009; Lafferty and Kuris, 2012), such as changes in food webs (Lefèvre et al. 2009; 
Lafferty and Kuris, 2012). Differences between infected and uninfected copepods seem more pronounced in a high food environment. Infected copepods are less likely to be consumed by sticklebacks before reaching infectivity, i.e. when $S$. solidus reduces activity (Weinreich et al. 2013), and more likely to be consumed thereafter, i.e. when $S$. solidus enhances activity (Wedekind and Milinski, 1996). While we do not know if the differences between feeding treatments are large enough to influence predation susceptibility, our results nonetheless indicate that behavioural differences between infected and uninfected copepods can depend on resource availability. This raises the possibility that $S$. solidus transmission to fish might be environmentally-dependent.

\section{SUPPLEMENTARY MATERIAL}

To view supplementary material for this article, please visit http://dx.doi.org/10.1017/pao.2015.3.

\section{ACKNOWLEDGEMENTS}

We would like to thank R. Leipnitz and M. Schwarz for technical assistance, I. Salmonte-Padilla for providing fish and two anonymous reviewers for helpful comments on an earlier version of the manuscript.

\section{FINANCIAL SUPPORT}

This work was supported by the Max Planck Society. N. H. received her funding through the International Max Planck Research School (IMPRS) for Evolutionary Biology. D. P. B. was partially supported by a DFG fellowship (BE 5336/1-1)

\section{CONFLICT OF INTEREST}

None.

\section{ETHICAL STANDARDS}

The authors assert that all procedures contributing to this work comply with the ethical standards of the relevant national and institutional guides on the care and use of laboratory animals.

\section{REFERENCES}

Adamo, S. A. (2012). The strings of the puppet master: how parasites change host behaviour. In Host Manipulation by Parasites (ed. Hughes, D. P., Brodeur, J. and Thomas, F.), pp. 36-51. Oxford University Press, Oxford.

Amat, F., Gozalbo, A., Navarro, J. C., Hontoria, F. and Varo, I. (1991). Some aspects of Artemia biology affected by cestode parasitism. Hydrobiologia 212, 39-44.

Baldauf, S. A., Thünken, T., Frommen, J. G., Bakker, T. C. M., Heupel, O. and Kullmann, H. (2007). Infection with an acanthocephalan manipulates an amphipod's reaction to a fish predator's odours. International fournal for Parasitology 37, 61-65.

Barber, I., Huntingford, F. A. and Crompton, D. W. T. (1995). The effect of hunger and cestode parasitism on the shoaling decisions of small freshwater fish. Fournal of Fish Biology 47, 524-536.
Bates, D., Maechler, M., Bolker, B. M. and Walker, S. (2014). lme4: linear mixed-effects models using Eigen and S4. Version 1.1-7. http:// CRAN.R-project.org $/$ package $=$ lme 4 .

Benesh, D. P. (2010a). What are the evolutionary constraints on larval growth in a trophically transmitted parasite? Oecologia 162, 599-608.

Benesh, D. P. (2010b). Developmental inflexibility of larval tapeworms in response to resource variation. International fournal for Parasitology 40, 487-497.

Benesh, D. P. and Hafer, N. (2012). Growth and ontogeny of the tapeworm Schistocephalus solidus in its copepod first host affects performance in its stickleback second intermediate host. Parasites and Vectors 5, 90.

Benesh, D. P., Valtonen, E. T. and Seppälä, O. (2008). Multidimensionality and intra-individual variation in host manipulation by an acanthocephalan. Parasitology 135, 617-626.

Benesh, D. P., Hasu, T., Seppälä, O. and Valtonen, E. T. (2009). Seasonal changes in host phenotype manipulation by an acanthocephalan: time to be transmitted? Parasitology 136, 219-230.

Benesh, D. P., Weinreich, F. and Kalbe, M. (2012). The relationship between larval size and fitness in the tapeworm Schistocephalus solidus: bigger is better? Oikos 121, 1391-1399.

Biron, D. G., Moura, H., Marché, L., Hughes, A. L. and Thomas, F. (2005). Towards a new conceptual approach to "parasitoproteomics". Trends in Parasitology 21, 162-168.

Cézilly, F., Grégoire, A. and Bertin, A. (2000). Conflict between cooccurring manipulative parasites? An experimental study of the joint influence of two acanthocephalan parasites on the behaviour of Gammarus pulex. Parasitology 120, 625-630.

Cézilly, F., Perrot-Minnot, M.-J. and Rigaud, T. (2014). Cooperation and conflict in host manipulation: interactions among macro-parasites and micro-organisms. Frontiers in Microbiology 5, 248.

Clarke, A. S. (1954). Studies on the life cycle of the pseudophyllidean cestode Schistocephalus solidus. Proceedings of the Zoological Society of London 124, 257-302.

Dianne, L., Rigaud, T., Léger, E., Motreuil, S., Bauer, A. and PerrotMinnot, M.-J. (2010). Intraspecific conflict over host manipulation between different larval stages of an acanthocephalan parasite. Fournal of Evolutionary Biology 23, 2648-2655.

Dianne, L., Perrot-Minnot, M.-J., Bauer, A., Elsa, L. and Rigaud, T. (2011). Protection first then facilitation: a manipulative parasite modulates the vulnerability to predation of its intermediate host according to its own developmental stage. Evolution 65, 2692-2698.

Dianne, L., Perrot-Minnot, M.-J., Bauer, A., Guvenatam, A. and Rigaud, T. (2014). Parasite-induced alteration of plastic response to predation threat: increased refuge use but lower food intake in Gammarus pulex infected with the acanothocephalan Pomphorhynchus laevis. International Fournal for Parasitology 44, 211-216.

Dubinina, M. N. (1980). Tapeworms (Cestoda, Ligulidae) of the Fauna of the USSR. Amerind Publishing Co. Pvt. Ltd., New Dehli.

Durieux, R., Rigaud, T. and Médoc, V. (2012). Parasite-induced suppression of aggregation under predation risk in a freshwater amphipod: sociality of infected amphipods. Behavioural Processes 91, 207-213.

Franceschi, N., Bollache, L., Cornet, S., Bauer, A., Motreuil, S. and Rigaud, T. (2010a). Co-variation between the intensity of behavioural manipulation and parasite development time in an acanthocephalan amphipod system. Fournal of Evolutionary Biology 23, 2143-2150.

Franceschi, N., Cornet, S., Bollache, L., DechaumeMoncharmont, F.-X., Bauer, A., Motreuil, S. and Rigaud, T. (2010b). Variation between populations and local adaptation in acanthocephalan-induced parasite manipulation. Evolution 64, 2417-2430.

Franz, K. and Kurtz, J. (2002). Altered host behaviour: manipulation or energy depletion in tapeworm-infected copepods? Parasitology 125, 187-196.

Giles, N. (1987). Predation risk and reduced foraging activity in fish experiments with parasitized and non-parasitized 3-spined sticklebacks, Gasterosteus-aculeatus L. Fournal of Fish Biology 31, 37-44.

Hafer, N. and Milinski, M. (2015). When parasites disagree: evidence for parasite-induced sabotage of host manipulation. Evolution 69, 611-620.

Haine, E. R., Boucansaud, K. and Rigaud, T. (2005). Conflict between parasites with different transmission strategies infecting an amphipod host. Proceedings of the Royal Society B 272, 2505-2510.

Hammerschmidt, K., Koch, K., Milinski, M., Chubb, J. C. and Parker, G. A. (2009). When to go: optimization of host switching in parasites with complex life cycles. Evolution 63, 1976-1986.

Holmes, J. C. and Bethel, W. M. (1972). Modification of intermediate host behaviour by parasites. Zoological fournal of the Linnean Society 51, 123-149. Hothorn, T., Bretz, F. and Westfall, P. (2008). Simultaneous inference in general parametric models. Biometrical fournal 50, 346-363. 
Jakobsen, P. J. and Wedekind, C. (1998). Copepod reaction to odor stimuli influenced by cestode infection. Behavioral Ecology 9, 414-418.

Labaude, S., Cézilly, F., Tercier, X. and Rigaud, T. (2015). Influence of host nutritional condition on post-infection traits in the association between the manipulative acanthocephalan Pomphorhynchus laevis and the amphipod Gammarus pulex. Parasites and Vectors 8, 403

Lafferty, K. D. and Kuris, A. M. (1999). How environmental stress affects the impacts of parasites. Limnology and Oceanography 44, 925-931. Lafferty, K. D. and Kuris, A. M. (2012). Ecological consequences of manipulative parasites. In Host Manipulation by Parasites (ed. Hughes, D. P., Brodeur, J. and Thomas, F.), pp. 158-168. Oxford University Press, Oxford. Lafferty, K. D. and Shaw, J. C. (2013). Comparing mechanisms of host manipulation across host and parasite taxa. The Fournal of Experimental Biology 216, 56-66.

Lefèvre, T., Lebarbenchon, C., Gauthier-Clerc, M., Missé, D., Poulin, R. and Thomas, F. (2009). The ecological significance of manipulative parasites. Trends in Ecology and Evolution 24, 41-48.

Maure, F., Brodeur, J., Ponlet, N., Doyon, J., Firlej, A., Elguero, E. and Thomas, F. (2011). The cost of a bodyguard. Biology Letters 7, 843-846. McElroy, E. J. and de Buron, I. (2014). Host performance as a target of manipulation by parasites: a meta-analysis. The Fournal of Parasitology 100, 399-410.

Milinski, M. (1990). Parasites and host decision-making. In Parasitism and Host Behaviour (ed. Barnard, C. J. and Behnke, J. M.), pp. 95-116. Taylor \& Francis Group, London.

Moore, J. (2002). Parasites and the Behavior of Animals. Oxford University Press, New York.

Moore, J. (2013). An overview of parasite-induced behavioral alterations and some lessons from bats. The fournal of Experimental Biology 216, 11-17. Parker, G. A., Ball, M. A., Chubb, J. C., Hammerschmidt, K. and Milinski, M. (2009). When should a trophically transmitted parasite manipulate its host? Evolution 63, 448-458.

Plaistow, S. J., Troussard, J. P. and Cézilly, F. (2001). The effect of the acanthocephalan parasite Pomphorhynchus laevis on the lipid and glycogen content of its intermediate host Gammarus pulex. International fournal for Parasitology 31, 346-351.

Ponton, F., Biron, D. G., Joly, C., Helluy, S., Duneau, D. and Thomas, F. (2005). Ecology of parasitically modified populations: a case study from a gammarid-trematode system. Marine Ecology Progress Series 299, 205-215.

Poulin, R. (1994a). Meta-analysis of parasite-induced behavioural changes. Animal Behaviour 48, 137-146.

Poulin, R. (1994b). The evolution of parasite manipulation of host behaviour: a theoretical analysis. Parasitology 109, 109-118.
Poulin, R. (2010). Parasite manipulation of host behavior: an update and frequently asked questions. Advances in the Study of Behavior 41, 151-186. Poulin, R. and Thomas, F. (1999). Phenotypic variability induced by parasites: extent and evolutionary implications. Parasitology Today 15, 28-32.

R Development Core Team (2010). R: A Language and Environment for Statistical Computing. Vienna (Austria): R Foundation for Statistical Computing.

Rasband, W. S. (2008). ImageJ. http://rsbweb.nih.gov/ij/

Roitberg, B. D. (2012). Parasites discover behavioral ecology: how to manage one's host in a complex world. In Host Manipulation by Parasites (ed. Hughes, D. P., Brodeur, J. and Thomas, F.), pp. 54-70. Oxford University Press, Oxford.

Smyth, J. D. (1946). Studies on tapeworm physiology I . The cultivation of Schistocephalus solidus in vitro. The Fournal of Experimental Biology 23, $47-70$.

Smyth, J. D. and McManus, D. P. (1989). The Physiology and Biochemistry of Cestodes. Cambridge University Press, Cambridge.

Thomas, F., Renaud, F., Demee, T. and Poulin, R. (1998). Manipulation of host behaviour by parasites: ecosystem engineering in the intertidal zone? Proceedings of the Royal Society B 265, 1091-1096.

Thomas, F., Poulin, R. and de Meeüs, T. (1999). Parasites and ecosystem engineering: what roles could they play? Oikos 84, 167-171.

Thomas, F., Adamo, S. A. and Moore, J. (2005). Parasitic manipulation: where are we and where should we go? Behavioural Processes 68, 185-199. Thomas, F., Brodeur, J., Maure, F., Franceschi, N., Blanchet, S. and Rigaud, T. (2011). Intraspecific variability in host manipulation by parasites. Infection, Genetics and Evolution 11, 262-269.

Thomas, F., Rigaud, T. and Brodeur, J. (2012). Evolutionary routes leading to host manipulation by parasites. In Host Manipulation by Parasites (ed. Hughes, D. P., Brodeur, J. and Thomas, F.), pp. 16-33. Oxford University Press, Oxford.

Vickery, W. L. and Poulin, R. (2009). The evolution of host manipulation by parasites: a game theory analysis. Evolutionary Ecology 24, 773-788. Wedekind, C. and Milinski, M. (1996). Do three-spined sticklebacks avoid consuming copepods, the first intermediate host of Schistocephalus solidus?-An experimental analysis of behavioural resistance. Parasitology 112, 371-383

Wedekind, C., Christen, M., Schärer, L. and Treichel, N. (2000) Relative helminth size in crustacean hosts: in vivo determination, and effects of host gender and within-host competition in a copepod infected by a cestode. Aquatic Ecology 34, 279-285.

Weinreich, F., Benesh, D. P. and Milinski, M. (2013). Suppression of predation on the intermediate host by two trophically-transmitted parasites when uninfective. Parasitology 140, 129-135. 